\title{
Environmental Fate of Antibiotics and Resistance Genes in Livestock Waste and Digestate from Biogas Plants
}

\author{
Anna Barra Caracciolo ${ }^{1}$, Andrea Visca ${ }^{1 *}$, Giulia Massini ${ }^{1,3}$, Luisa Patrolecco ${ }^{2}$, Valentina Mazzurco Miritana ${ }^{1,3}$, \\ Paola Grenni ${ }^{1}$ \\ ${ }^{1}$ Water Research Institute-National Research Council (IRSA-CNR), Rome, Italy \\ ${ }^{2}$ Institute of Polar Sciences (ISP-CNR), Rome, Italy \\ ${ }^{3}$ Department of Energy Technologies, Italian Nation Agency for New Technologies, Energy and Sustainable Economic Development \\ (ENEA), Rome, Italy
}

Received Date: July 30, 2020; Accepted Date: Aug 05, 2020; Published Date: Aug 17, 2020

*Corresponding Author: Andrea Visca, Water Research Institute-National Research Council (IRSA-CNR), Rome, Italy. Tel: +390690672045; Email: visca@irsa.cnr.it

\section{Abstract}

Huge amounts of antibiotics are currently being used in both human and veterinary medicine. Moreover, most are recalcitrant to biodegradation and can persist in the environment. In fact these compounds have been increasingly found as micro-contaminants in natural ecosystems and cause particular concern because of the development of multi-resistant bacteria, posing serious risks for human and animal health. In particular, the antibiotics used in livestock farms can persist in manure, causing environmental contamination if used as a biofertilizer. However, farm manure can also be a feed for biogas reactors and the digested effluent (digestate) used as fertilizer or soil improver. The fact that the latter can still contain antibiotic residues and possibly antibiotic resistance genes still remains to be clarified.

Keywords: Anaerobic Digestion; ARGs; Cattle Manure; Ciprofloxacin; Enrofloxacin; Microbial Community; Sulfamethoxazole

\section{Introduction}

Italy is the second country in Europe for the number of anaerobic digestion plants (Statistical report 2018 of European Biogas Association). Although they were initially set up with the main purpose of solving the issue of farm waste disposal, the production of electricity (by on-site combustion of biogas) now constitutes another source of income for agricultural firms, like milk and meat production. It is well known that it is common in cattle farms to use antibiotics for treating animal diseases [1]. However, residues of antibiotics and antibiotic resistance genes (ARGs) are nowadays considered environmentally emerging contaminants [2-4] posing a risk of spreading of antibiotic resistance among natural, human and animal microbial populations. Moreover, antibiotics themselves can also affect some sensitive natural microbial populations with possible consequences for some key ecosystem functions [5].

The overuse of antibiotics to counteract animal diseases and in arable farming, such as the utilization of manure and bio solids as fertilizers $[6,7]$ and the use of reclaimed water, have been significantly contributing to the environmental contamination from antibiotics and to the selection of antibiotic resistance genes [8-10]. The selection and transmission of ARGs, which give resistance bacteria (ARB) the ability to overcome the effects of antibiotics, is a phenomenon well known in hospitals [11], where antibiotic resistant pathogenic bacteria can persist and infect patients in the nosocomial environment in different ways [12]. Consequently, an increasing number of infections are becoming harder to treat owing to antibiotic ineffectiveness [13-16]. The origin of antibiotic resistance genes in microorganisms is older than the antibiotic era $[\mathbf{1 7}, \mathbf{1 8}]$, because ARGs are commonly found in natural bacteria [9]. However, the scientific 
community is now aware that the spreading of ARB and ARGs is a complex phenomenon, involving both the indoor environments where antibiotics are used and soil and water ecosystems, where they are present as micro-contaminants $[\mathbf{1 9}, \mathbf{2 0}]$, in line with the One Health approach, which recognizes that human health is connected to that of animals and the environment. The holistic One Health concept is ancient and up-to-date at the same time and is based on the recognition that human, animal and ecosystem health are inextricably linked. This model has been recognized by several Ministries of Health and Environment worldwide, the European Commission and the World Health Organization [21-23].

In antibiotic treated animals, gut bacteria can act as ARG reservoirs [24], potentially transferring genetic material to soil and water environmental microorganisms and from the latter directly or indirectly to humans, for example through the consumption of fresh vegetables (Fig. 1) [25-28]. The European Commission has recently promoted the European Green Deal [29], a series of actions aimed at boosting the efficient use of resources, with a view to achieving a clean, circular economy and restoring biodiversity and reducing pollution. Among the various actions, the so called «Farm to Fork » one [30] recognizes the link between humans and ecosystems, where the One Health concept is reiterated. Antimicrobial resistance due to the massive use of antibiotics worldwide has led to thousands of human deaths and considerable healthcare costs. The Commission aims to reduce the overall use of antibiotics for farmed animals by $50 \%$ by 2030 .



Figure 1. Farming practices and the potential path for the spreading of ARB and ARGs. Can Anaerobic Digestion influence (decrease/increase) ARB and ARGs in the digestate used as a good quality and environmentally friendly fertilizer?

Moreover, the spread of ARGs through microbial communities can also be favored by other chemicals [31]. The coexistence of antibiotic-producing and non-producing bacterial strains has led to the co-evolution of resistance mechanisms in environments where antibiotics are not present, due to the co-selection of ARGs with other genes conferring, for example, resistance to heavy metals or other pollutants such as polycyclic aromatic hydrocarbons $[32,33]$. This is due to the fact that ARGs are commonly located on genetic cassettes associated with several genes and linked to integrases, placed on plasmids. ARGs can be transferred between different bacterial species due to their association with integrons and mobile genetic elements (MGEs), such as transposons and plasmids [34, 35].

In particular, ARGs can be transferred by one microorganism to another by vertical gene transfer (VGT) inside the same bacterial species, and by horizontal gene transfer (HGT) between different species through MGEs [36]. Once in the soil, intestinal bacteria mix with soil ones carrying genetic material useful for evolutionary adaptation [37]. Several studies have investigated if residual 
antibiotics and ARGs from cattle manure can alter the natural environmental resistome, showing a general increase in ARG abundances [38]. For example, different classes of antimicrobials have been detected in cattle manure, in particular fluoroquinolones, sulfonamides and tetracyclines in US beef cattle manure [39]. In a comprehensive study, Zhao et al. found seven fluoroquinolones, eight sulfonamides, and four tetracyclines in manure from largescale animal feedlots in China [40]. Overall, fluoroquinolones and tetracyclines were detected more frequently and at higher concentrations than sulfonamides (oxytetracycline, $1.24 \mathrm{mg} / \mathrm{kg}$; enrofloxacin, $6.79 \mathrm{mg} / \mathrm{kg}$; ciprofloxacin, $3.44 \mathrm{mg} / \mathrm{kg}$; sulfamethoxazole, not detected). In a similar way, the number of genes associated with resistance to these antibiotics and found in manure and in soil amended with it was considerable [28].

\section{Anaerobic Digestion}

An alternative to the direct application of manure on agricultural land is its use as feed for anaerobic digesters, in order to obtain biogas to produce electricity, heat or fuel [41, 42]. Anaerobic digestion (AD) is a spontaneous process, widespread in environments rich in organic matter but depleted of oxygen and other electron acceptors such as nitrate, sulfate, iron or oxidized manganese [43]. These ecosystems include shallow freshwaters such as swamps, rice fields and submerged soils, but also human and animal intestinal tracts (large ruminant and non-ruminant herbivores, as well as termites and woodworms). Anthropogenic and engineered environments, such as landfills and anaerobic digesters, are also included [44]. The AD technology is spreading rapidly [45] due to the numerous advantages it offers. In addition to the well-known possibility of connecting waste disposal with sustainable energy production and using the digestate as a fertilizer [46], other benefits for society and the environment are the increase in nutrient recovery and the reduction of greenhouse emissions [47]. Moreover, from a technological point of view, AD has been developed as a low- cost organic waste treatment technology with a simple setup and relatively limited investment and operating costs [48]. All these reasons currently place the anaerobic digestion process and biogas in a hub position in the development of the circular economy, especially in the biomethane production perspective.

The AD process consists of a sequence of anaerobic biochemical reactions mediated by populations of microorganisms that, cooperating sequentially [49], convert complex organic molecules, such as polysaccharides, lipids, and proteins, into simple substances, mainly $\mathrm{CH}_{4}(50-75 \%)$ and $\mathrm{CO}_{2}(25-45 \%)$. During $\mathrm{AD}$ small quantities of other gases are also produced, such as $\mathrm{H}_{2} \mathrm{O}, \mathrm{H}_{2}, \mathrm{CO}, \mathrm{N}_{2}, \mathrm{NH}_{3}, \mathrm{O}_{2}$, and $\mathrm{H}_{2} \mathrm{~S}$, whose overall fraction is approximately $5 \%$ of the biogas produced $[\mathbf{5 0 , 5 1}]$.

The AD process includes four main metabolic steps: (i) hydrolysis, (ii) acidogenesis and (iii) acetogenesis, which are performed by Bacteria and (iv) methanogenesis, the last step, carried out by the methanogenic Archaea.

Since an unbalanced composition of the microbial community affects biogas production efficiency, microbial ecology studies are fundamental for successful AD. In the last decade, many works have been focusing on understanding the structure and dynamics of the archaeal and bacterial communities during the AD process. $[\mathbf{6 , 4 6 , 4 8}]$. For example, some authors showed that due to their bacteriostatic and/or biocide effects, antibiotics can affect $\mathrm{AD}$ performance and reduce biogas production, primarily by selectively influencing microbial components and thus changing the general structure of the microbial community [52]. Key populations of acetogenic bacteria, capable of converting volatile acids such as propionate and butyrate into acetate (which in turn can be directly used by acetoclastic archaea to produce methane) are reported to be sensitive to the detrimental actions of antibiotics [53]. Other authors reported that antibiotics such as sulfamethoxazole can trigger significant changes in methanogen composition, by driving it towards a predominance of the acetotrophic or hydrogenotrophic metabolic pathway in the production of methane [54, 55]. The consequences in terms of overall $\mathrm{AD}$ efficiency are still unclear.

To date, few studies have been conducted on the interaction between antibiotics and sulfate-reducing bacteria (SRB), developing $\mathrm{H} 2 \mathrm{~S}$ during $\mathrm{AD}$. A microbial compositional analysis revealed that anaerobic reactors receiving antibiotic-bearing (mainly streptomycin) wastewater were dominated by Deltaproteobacteria (51\%) affiliated mainly with sulfatereducing bacteria (SRB) [56]. The latter can have a detrimental effect on biogas production because they can compete with Archaea [57] and because $\mathrm{H}_{2} \mathrm{~S}$ can be toxic for other anaerobes.

Although these studies showed that the presence of antibiotics can affect $\mathrm{AD}$ performance, the possible removal of antibiotic residues during the AD process has not been sufficiently investigated so far, especially in cattle manure fed anaerobic digesters [58, 59]. Some studies reported that degradation of various antibiotics during AD can occur; in fact, a complete removal of ampicillin, florfenicol, sulfadimethoxine, sulfamerazine, sulfamethoxazole, sulfamethoxydiazine, tetracycline, trimethoprim, and tylosin was observed [60-62].

However, these works focused more on the effects of antibiotics on the $\mathrm{AD}$ process than on the removal of antibiotics by the microbial community. It has been hypothesized that antibiotics can act as a selective pressure on some microbial components, which can develop resistance. In some cases, microorganisms can resist the toxic effects of antibiotics; in others they can show the capability to degrade and remove them as a homeostatic response to stress. [5]. This hypothesis is supported by the fact that there is also substantial evidence that antibiotic compounds (at some concentrations) do not completely affect $\mathrm{AD}$ process stability as measured by biogas production and composition, $\mathrm{pH}$, volatile fatty acids (VFAs) concentrations, soluble organic content in the AD process, volatile solids removal or nitrogen content $[\mathbf{2 8 , 6 3 , 6 4 ]}$. In any case, the effects of antibiotics on the $\mathrm{AD}$ microbial community depend on several parameters, and, primarily, their concentration [65].

Another aspect to be still clarified is if the AD process can influence the fate of ARGs; some studies report that anaerobic digestion can reduce tet genes (tetracycline resistance genes), [63] and others that AD can promote an increase in sul genes at the end of the process. [28, 64]. Further studies are therefore 
necessary to investigate more thoroughly the possible interactions between antibiotic residues, the AD process and ARGs.

\section{Sulfonamides and Fluoroquinolones}

Among the different classes of antibiotics used for cattle, there are sulfonamides and fluoroquinolones. Sulfonamides are one of the oldest classes of drugs used systemically. Gerhard Domagk, a Nobel Prize winner in 1939, first discovered their anti-bacterial properties; he observed that prontosil, a sulfonamide dye, was able to restrain selectively infectious bacteria cells. Prontosil is a pro-drug, which is transformed by the human body to sulfanilamide, the anti-bacterial active agent. This finding led to the discovery of other anti-bacterial compounds derived from this chemical group, with the same main core, but different bioactivities [66]. Currently, sulfamethoxazole (SMX) is one of the antibiotics most commonly prescribed and consumed in both human and veterinary medicine. In particular, SMX can be used in combination with the antibiotic Trimethoprim to treat and prevent respiratory infections and mastitis in cattle. SMX is a sulfonamide compound with aniline and an isoxazole group. Its action is bacteriostatic; it is able to inhibit the synthesis of folic acid, necessary for the synthesis of nucleotides, in bacterial cells (Fig. 2a). Many bacteria are able to convert paraaminobenzoic acid to folic acid. Since sulfonamides are very similar in structure to para-amino benzoic acid, they can act as competitive inhibitors of it, by interrupting its role in the synthesis of folic acid and ultimately, of purine and DNA [67]. Once administered, SMX is not completely metabolized: approximately $43 \%$ is transformed to $\mathrm{N}_{4}$-acetylsulfamethoxazole, $9-15 \%$ to sulfamethoxazole $\mathrm{N}_{1}$ - glucuronide and $15-25 \%$ is excreted unchanged [68, 69]. Some authors found SMX degradation from $50 \%$ to $80 \%$ in biologically active soils in about 20 days, under respectively aerobic and anaerobic conditions [70, 71]. Although this antibiotic can be biodegraded [7], a reduction in soil bacterial diversity and increase in the number of ARB is expected in agricultural soils. Finally, another issue to be investigated is the possible accumulation of SMX into fresh edible vegetables [72, 73] which can be a source of ARB and ARG for humans.

Resistance to sulfonamides, clinically present in gramnegative enteric bacteria, is transmitted by plasmids and influenced by genes that encode alternative variants of drugresistant DHPS enzymes. Dihydropteroate synthase (DHPS) catalyzes the reaction of 6-hydroxymethyl-dihydropterin 1'diphosphate with 4-aminobenzoate producing dihydropteroate and inorganic pyrophosphate [74]. Sulfonamides act as competitive inhibitors of DHPS. Enzymes encoded by resistance-plasmids correspond to two genes, sull and sul2. The sull gene is usually found linked to other resistance genes in the Tn21 type integron, while sul2 is usually found on small plasmids of the IncQ family (RSF1010) and of the pBP1 one. DHPS products of both sull and sul2 show low $\mathrm{K}_{\mathrm{m}}$ values (0.6 $\mu \mathrm{M}$ ) for para-aminobenzoic acid (PABA), resulting in resistance to high concentrations of sulfonamide (Fig. 3a). In particular, sul2's DHPS appears to show a very acute specificity in distinguishing between its normal PABA substrate and sulfonamide. Moreover, a third resistance gene, sul3, has been characterized by Perreten and Boerlin [75], coding for a 263- amino-acid protein similar to a dihydropteroate synthase encoded by the 54-kb conjugative plasmid pVP440 from Escherichia coli.

Quinolones are one of the most frequently prescribed types of antimicrobials in the world and are used to treat various human bacterial infections [76]. Due to their widespread use and overuse, the number of quinolone-resistant bacterial strains has steadily increased since the 1990s [77]. As well as other antimicrobials, the increase in quinolone resistance threatens the clinical applicability of this class of drugs. Quinolones are able to convert their targets, gyrase and topoisomerase IV, into toxic enzymes that fragment bacterial chromosomes [78] (Fig. 2b). Norfloxacin, the first broad-spectrum quinolone, was restricted to use in the treatment of urinary tract infections and sexually transmitted diseases. Currently, fluoroquinolones (FQs), fully synthetic and broad-spectrum antibiotics, are the most frequently used in animal husbandry [79]. They derive from quinolones by modifying their structure with a fluorine

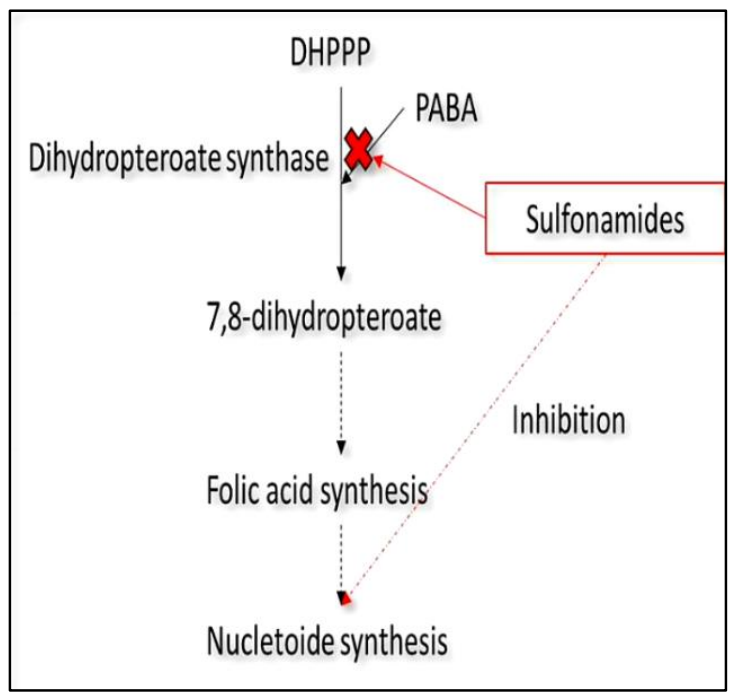

(a)

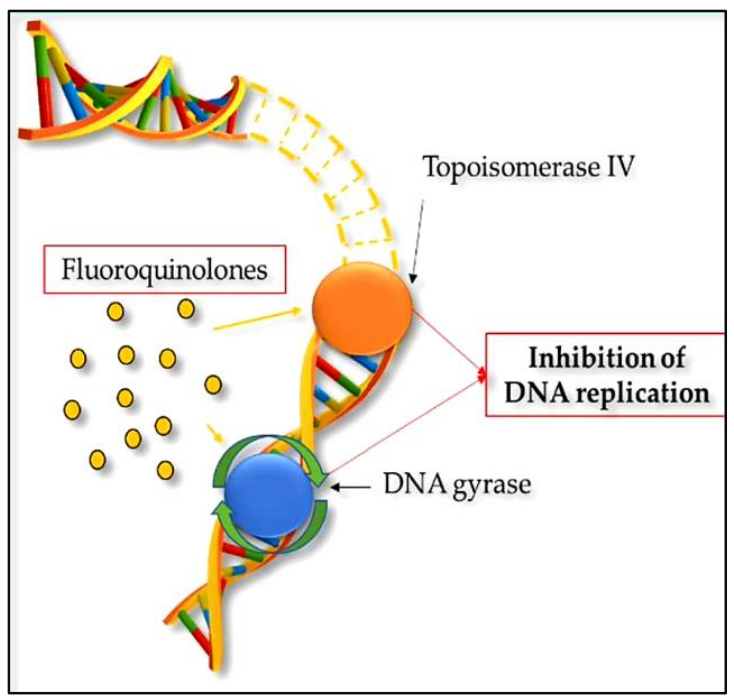

(b) 
Figure 2: Mechanism of action in bacterial cells of (a) sulfonamides, such as sulfamethoxazole and (b)

fluoroquinolones such as ciprofloxacin and enrofloxacin.

Ciprofloxacin (CIP) was the first fluoroquinolone that displayed significant activity not only in the urinary tract [80]. For more than 20 years, ciprofloxacin has continued to be one of the most commonly prescribed antibacterial drugs and used to treat a variety of Gram-negative and to a lesser extent, Grampositive infections. The clinical success of ciprofloxacin spawned an array of newer-generation quinolones that displayed an even broader spectrum of activity, especially against Grampositive species [80]. A consequence of its massive use is the inclusion of CIP in the Watch List by EU (2018) [81].

Enrofloxacin (ENR) is another broad-spectrum antibiotic related to the class of fluoroquinolones [82]. It has been widely used in many countries for the treatment of a variety of poultry diseases, mainly those associated with Escherichia coli and Pasteurella multocida, but also avian mycoplasmosis. In the United States, the usage of enrofloxacin in poultry was banned in 2005. However, FQ-resistant strains are still found [83]. Enrofloxacin and ciprofloxacin are closely related, since the latter is the main metabolite of ENR [84]. Even if CIP is not directly applied to livestock, metabolization of ENR could end in the occurrence of CIP in veterinary field. Both ENR and CIP are adsorbed to soil and their biodegradation rates are quite low, consequently significant concentrations of $\mathrm{FQ}$ are found in agricultural soil $[\mathbf{4 0 , 8 5}$ ]. FQ persistence in soil depends on both abiotic (e.g. light, soil organic matter) and biotic factors (bacterial populations able to degrade them) [86]. On the other hand, strong adsorption lead to less uptake of FQs residues by plants [87]. Once in the soil, the fate of this class of antibiotics in the ecosystem food web (including human one) is still to be clarified [88].

Several resistance mechanisms induced by quinolones in bacteria cells are reported [89] such as those related to a chromosomal mutation in genes encoding for topoisomerase IV or gyrase IV, or to a decrease in drug accumulation (Fig. 3). The latter can happen if bacterial efflux pumps are overexpressed (and the drug is pumped outside the cell), or when porin proteins are down-regulated, avoiding the passive diffusion of ciprofloxacin inside the cell. Moreover, so-called plasmid-mediated quinolone resistance has been recognized. It acts in different ways: the first plasmid-mediated resistance discovered was the $q n r$ gene, encoding for a pentapeptide capable of binding chromosomal DNA and protecting it from drug action. Another plasmid-mediated resistance mechanism is the $c r$ variant of the $a a c\left(6^{\prime}\right)-l b$ gene, which encodes for an aminoglycoside acetyltransferase that acetylates ciprofloxacin[90].

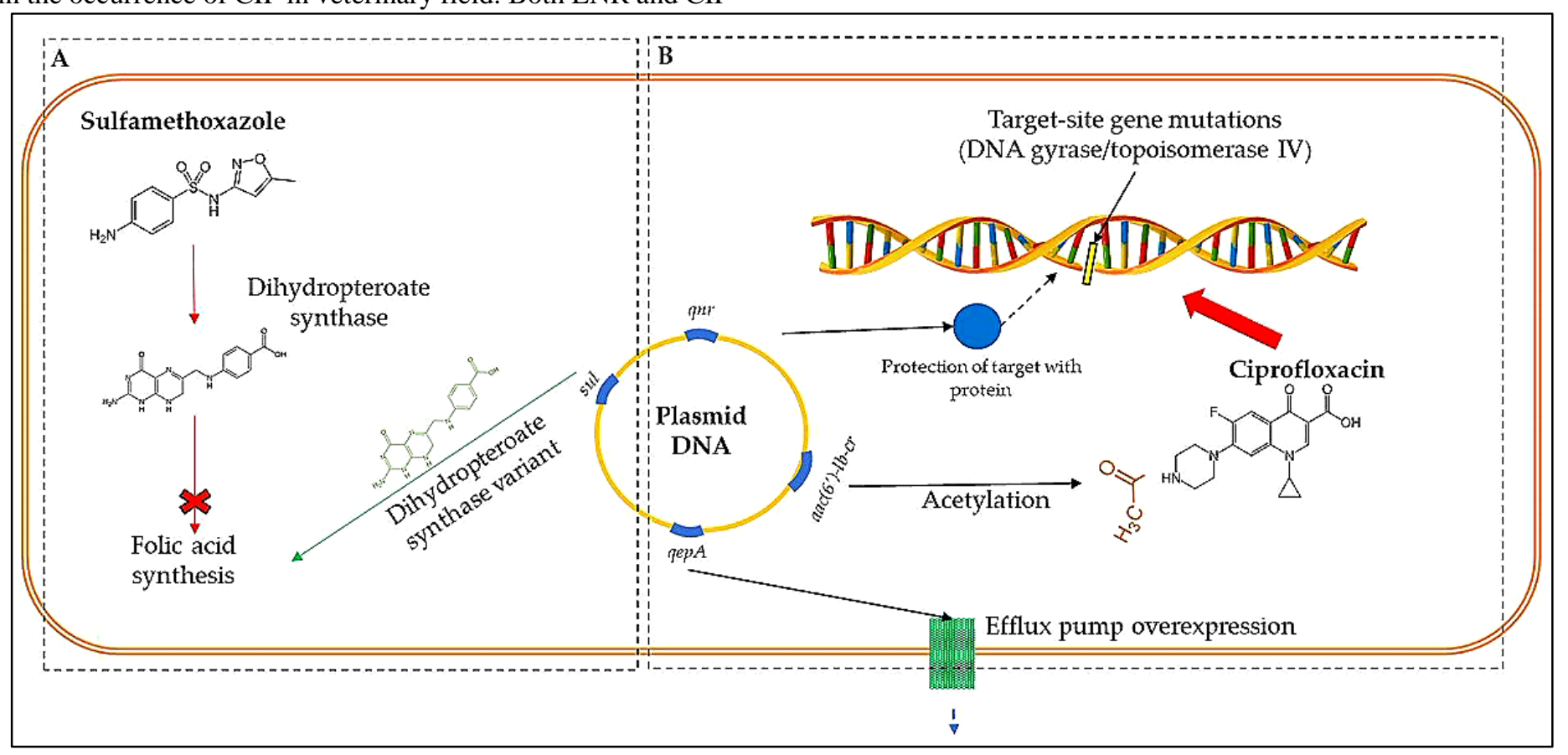

Figure 3. Resistance mechanisms for sulfonamides (A) and fluoroquinolones (B).

\section{The AZeRO Antibiotics Project}

Within this context, the project titled "Evaluation of the presence of Antibiotics in Zootechnical waste and in the digestate of biogas plants: study of strategies for their RemO $\boldsymbol{O}$ val - AZeRO antibiotics" is a research project funded by Lazio Innova (Lazio Regional Development Agency) in line with environmental sustainability, the green economy and the protection of human health and ecosystems. It is an interdisciplinary project where the microbial ecology, soil and ruminal ecosystems, environmental and fermentation chemistry and molecular biology interact in order to investigate the $\mathrm{AD}$ process and how antibiotics can affect it. Moreover, the environmental fate of antibiotics and ARGs is also studied.

In particular, the project aims at: 
- evaluating the presence and concentration of SMX, CIP and ENR antibiotics in zootechnical waste and in the digestate of full-scale biogas digesters in the Lazio region, (Central Italy);

- assessing how SMX, CIP and ENR occurrence can influence the anaerobic digestion process;

- assessing which factors and conditions can favor antibiotic degradation in anaerobic conditions;

- Identifying ecological solutions and "best practices" for preventing or reducing the environmental spreading of residual antibiotics and ARGs by agricultural activities.

- Evaluating if the $\mathrm{AD}$ process is able to decrease the antibiotics and ARGs which enter biogas digesters with manure. The latter aspect is particularly important because it could make digestate more suitable for replacing chemical fertilizers and meet the European Green Deal target "From Farm to Fork" [30].

The two-year project will involve several biogas plants located in cattle farms in central Italy, where milk, meat and cheeses, including numerous PDO (Protected Designation of Origin) and PGI (Protected Geographical Indication), are produced. Both the reactor feeds (mainly cattle manure) and digestates will be sampled in those farms monthly, over 2 year to evaluate the residual concentrations of antibiotics and the resistance genes.

\section{Author Contributions}

"Conceptualization, A.V. and A.B.C.; methodology, A.V., V.M.M., P.G., L.P., G.M. and A.B.C.; resources, A.B.C., L.P. and G.M.; data curation, A.V., V.M.M., P.G., L.P., G.M. and A.B.C.; writing - original draft preparation, A.V.; writingreview and editing, V.M.M., P.G., L.P., G.M. and A.B.C.; supervision, A.B.C. and G.M.; project administration, A.B.C.; funding acquisition, A.B.C and G.M. All authors have read and agreed to the published version of the manuscript."

\section{Funding}

"The project Azero Antibiotics, N. 85-2017-15065 was funded by Lazio Innova (Progetti di Gruppi di Ricerca Programma strategico Regionale per la ricerca, innovazione ed il trasferimento tecnologico 2017-2020)"

\section{Conflicts of Interest}

The authors declare no conflict of interest. The funders had no role in the design of the study, in the collection, analysis or interpretation of the data, in the writing of the manuscript or in the decision to publish the results.

\section{References}

1. Brandt KK; Amézquita A; Backhaus T; Boxall A; Coors A et al. (2015) Ecotoxicological assessment of antibiotics: A call for improved consideration of microorganisms. Environ Int 85:189-205.

2. Barra Caracciolo A; Topp E; Grenni P (2014) Pharmaceuticals in the environment: Biodegradation and effects on natural microbial communities. A review. J Pharm Biomed Anal 106:25-36.

3. Alistair BA Boxall (2004) The environmental side effects of medication. EMBO Rep 5:1110-1116.

4. Carvalho IT; Santos L (2016) Antibiotics in the aquatic environments: A review of the European scenario. Environ Int 94:736-757.

5. Grenni P; Ancona V; Barra Caracciolo A (2018) Ecological effects of antibiotics on natural ecosystems: A review. Microchem. J 136: 25-39.

6. Ferguson RMW; Coulon F; Villa R (2018) Understanding microbial ecology can help improve biogas production in AD. Sci Total Environ 642:754-763.

7. Rauseo J; Barra Caracciolo A; Ademollo N; Cardoni M; Di Lenola $M$ et al. (2019) Dissipation of the antibiotic sulfamethoxazole in a soil amended with anaerobically digested cattle manure. J Hazard Mater 378.

8. Shi L; Ge B; Liu B; Liu X; Jiang M et al. (2019) Impact of Wuyiencin Application on the Soil Microbial Community and Fate of Typical Antibiotic Resistance Genes. Sci Rep 9.

9. Allen HK; Donato J; Wang HH; Cloud-Hansen KA; Davies J (2010) Call of the wild: Antibiotic resistance genes in natural environments. Nat Rev Microbiol 8:251259.

10. Zhang YJ; Hu HW; Chen QL; Singh BK; Yan H et al. (2019) Transfer of antibiotic resistance from manureamended soils to vegetable microbiomes. Environ Int 130.

11. Mulvey MR; Simor AE (2009) Antimicrobial resistance in hospitals: How concerned should we be? CMAJ 180:408415.

12. Almagor J; Temkin E; Benenson I; Fallach N; Carmeli Y (2018) The impact of antibiotic use on transmission of resistant bacteria in hospitals: Insights from an agent-based model. PLoS One 13:e197111.

13. Aarestrup FM (2005) Veterinary drug usage and antimicrobial resistance in bacteria of animal origin. Basic Clin Pharmacol Toxicol 96:271-281.

14. Kümmerer K (2009) Antibiotics in the aquatic environment - A review - Part I. Chemosphere 75:417-434.

15. Thiele-Bruhn S (2003) Pharmaceutical antibiotic compounds in soils-a review. J Plant Nutr Soil Sci 166:145-167.

16. Pawlowski AC; Wang W; Koteva K; Barton HA; McArthur AG et al. (2016) A diverse intrinsic antibiotic resistome from a cave bacterium. Nat Commun 7:13803.

17. Kirby WMM (1944) Extraction of a highly potent penicillin inactivator from penicillin resistant staphylococci. Science 99:452-453.

18. Peterson E; Kaur P (2018) Antibiotic resistance mechanisms in bacteria: Relationships between resistance determinants of antibiotic producers, environmental bacteria, and clinical pathogens. Front Microbiol 9: 2928. 
19. Kraemer SA; Ramachandran A; Perron GG (2019) Antibiotic pollution in the environment: From microbial ecology to public policy. Microorganisms 7:180.

20. Graham DW; Bergeron G; Bourassa MW; Dickson J; Gomes F et al. (2019) Complexities in understanding antimicrobial resistance across domesticated animal, human, and environmental systems. Ann N Y Acad Sci 1441:17-30.

21. Lebov J; Grieger K; Womack D; Zaccaro D; Whitehead N et al. (2017) A framework for One Health research. One Heal 3:44-50.

22. Organization WH; Food; of the United Nations AO (2016) for Animal Health, W.O. Antimicrobial resistance: a manual for developing national action plans; version 1 . World Health Organization 1-32.

23. CVMP Reflection paper on antimicrobials in the environment; 2018.

24. Lee K; Kim D; Lee D; Kim Y; Bu J et al. (2020) Mobile resistome of human gut and pathogen drives anthropogenic bloom of antibiotic resistance 1-14.

25. Wellington EMH; Boxall ABA; Cross P; Feil EJ; Gaze WH et al. (2013) The role of the natural environment in the emergence of antibiotic resistance in Gram-negative bacteria. Lancet Infect Dis 13:155-165.

26. Pan M; Chu LM (2017) Transfer of antibiotics from wastewater or animal manure to soil and edible crops. Environ Pollut 231:829-836.

27. Cerqueira F; Matamoros V; Bayona JM; Berendonk TU; Elsinga $G$ et al. (2019) Antibiotic resistance gene distribution in agricultural fields and crops. A soil-to-food analysis. Environ Res 177:18-26.

28. Wang F; Xu M; Stedtfeld RD; Sheng H; Fan J et al. (2018) Long-Term Effect of Different Fertilization and Cropping Systems on the Soil Antibiotic Resistome 52:13037-13046.

29. A European Green Deal | European Commission (accessed on Jul 15, 2020).

30. From Farm to Fork | European Commission (accessed on Jul 15, 2020).

31. Fu Q; Malchi T; Carter L; Li H; Gan JJ (2019) Pharmaceutical and Personal Care Products: From Wastewater Treatment into Agro-food Systems. Environ Sci Technol 53:14083-14090.

32. Bengtsson-Palme J; Kristiansson E; Larsson DGJ (2018) Environmental factors influencing the development and spread of antibiotic resistance. FEMS Microbiol Rev 42:68-80.

33. Chen WR; Huang CH (2012) Surface adsorption of organoarsenic roxarsone and arsanilic acid on iron and aluminum oxides. J Hazard Mater 227-228:378-385.

34. Mazel D (2006) Integrons: Agents of bacterial evolution. Nat Rev Microbiol 4:608-620.

35. Netherwood T; Bowden R; Harrison P; O'Donnell AG; Parker DS et al. (1999) Gene transfer in the gastrointestinal tract. Appl. Environ. Microbiol 65:5139-5141.

36. Sun D; Jeannot K; XiaoY; Knapp CW (2019) Editorial: Horizontal Gene Transfer Mediated Bacterial Antibiotic Resistance. Front. Microbiol 10:1933.
37. Wright GD (2010) Antibiotic resistance in the environment : a link to the clinic ? Curr Opin Microbiol 13:589-594.

38. Zhu Y; Johnson TA; Su J; Qiao M; Guo G (2013) Diverse and abundant antibiotic resistance genes in Chinese swine farms 110:3435-3440.

39. Van Epps A; Blaney L (2016) Antibiotic Residues in Animal Waste: Occurrence and Degradation in Conventional Agricultural Waste Management Practices. Curr Pollut Reports 2:135-155.

40. Zhao L; Dong YH; Wang H (2010) Residues of veterinary antibiotics in manures from feedlot livestock in eight provinces of China Sci Total Environ 408:1069-1075.

41. Scarlat N; Dallemand JF; Fahl F (2018) Biogas: Developments and perspectives in Europe. Renew Energy 129:457-472.

42. Nasir IM; Mohd Ghazi TI; Omar R (2012) Anaerobic digestion technology in livestock manure treatment for biogas production: A review. Eng Life Sci 12:258-269.

43. Schink B (1997) Energetics of syntrophic cooperation in methanogenic degradation. Microbiol Mol Biol Rev 61:262-280.

44. Gould MC (2015) Bioenergy and Anaerobic Digestion. In Bioenergy; Elsevier 297-317.

45. Lora Grando R; de Souza Antune AM; da Fonseca FV; Sánchez A; Barrena R (2017) Technology overview of biogas production in anaerobic digestion plants: A European evaluation of research and development. Renew. Sustain. Energy Rev 80:44-53.

46. De Vrieze J; Verstraete W (2016) Perspectives for microbial community composition in anaerobic digestion: from abundance and activity to connectivity. Environ Microbiol 18:2797-2809.

47. Chynoweth DP; Owens JM; Legrand R (2001) Renewable methane from anaerobic digestion of biomass. Renew Energy 22:1-8.

48. Castellano-Hinojosa A; Armato C; Pozo C; GonzálezMartínez A; González-López J (2018) New concepts in anaerobic digestion processes: recent advances and biological aspects. Appl Microbiol Biotechnol 102:50655076.

49. Manchala KR; Sun Y; Zhang D; Wang Z-W (2017) Anaerobic Digestion Modelling. Advances in Bioenergy 2:69-141.

50. Kiang Y-H (2018) other and emerging alternative energy technology. Fuel Property Estimation and Combustion Process Characterization; Elsevier 363-401.

51. Breeze P (2018) Waste to Energy Technologies. In Energy from Waste; Elsevier 29-37.

52. Ke X; Wang C yong; Li R dong; Zhang Y (2014) Effects of Oxytetracycline on Methane Production and the Microbial Communities During Anaerobic Digestion of Cow Manure. J Integr Agric 13:1373-1381.

53. Mai DT; Stuckey DC; Oh S (2018) Effect of ciprofloxacin on methane production and anaerobic microbial community. Bioresour Technol 261:240-248. 
54. Demirel B; Scherer P (2008) The roles of acetotrophic and hydrogenotrophic methanogens during anaerobic conversion of biomass to methane: A review. Rev Environ Sci Biotechnol 7:173-190.

55. Cetecioglu Z; Ince B; Orhon D; Ince O (2012) Acute inhibitory impact of antimicrobials on acetoclastic methanogenic activity. Bioresour Technol 114:109-116.

56. Deng Y; Zhang Y; Gao Y; Li D; Liu R et al. (2012) Microbial community compositional analysis for series reactors treating high level antibiotic wastewater. Environ Sci Technol 46:795-801.

57. Muyzer G; Stams AJM (2008) The ecology and biotechnology of sulphate-reducing bacteria. Nat Rev Microbiol 6:441-454.

58. Marti E; Gros M; Boy-Roura M; Ovejero J; Busquets AM et al. (2020) Pharmaceuticals removal in an on-farm pig slurry treatment plant based on solid-liquid separation and nitrification- denitrification systems. Waste Manag 102:412-419.

59. Gros M; Marti E; Balcázar JL; Boy-Roura M; Busquets A et al. (2019) Fate of pharmaceuticals and antibiotic resistance genes in a full-scale on-farm livestock waste treatment plant. J Hazard Mater 378.

60. Arikan OA (2008) Degradation and metabolization of chlortetracycline during the anaerobic digestion of manure from medicated calves. J Hazard Mater 158:485-490.

61. Mitchell SM; Ullman JL; Teel AL; Watts RJ; Frear C (2013) The effects of the antibiotics ampicillin, florfenicol, sulfamethazine, and tylosin on biogas production and their degradation efficiency during anaerobic digestion. Bioresour Technol 149:244-252.

62. Pansieri S; D'Imporzano G; Pognani M; Cavalli M; Chiesa L et al. (2013) Effect of veterinary antibiotics on biogas and bio-methane production. Int. Biodeterior Biodegrad 85:205-209.

63. Ince B; Coban H; Turker G; Ertekin E; Ince O (2013) Effect of oxytetracycline on biogas production and active microbial populations during batch anaerobic digestion of cow manure. Bioprocess Biosyst Eng 36:541-546.

64. Massé DI; Lu D; Masse L; Droste RL (2000) Effect of antibiotics on psychrophilic anaerobic digestion of swine manure slurry in sequencing batch reactors. Bioresour Technol 75:205-211.

65. Cheng DL; Ngo HH; Guo WS; Chang SW; Nguyen DD et al. (2018) Problematic effects of antibiotics on anaerobic treatment of swine wastewater. Bioresour Technol 263:642-653.

66. Kołaczek A; Fusiarz I; Lawecka J; Branowska D (2014) Biological activity and synthesis of sulfonamide derivatives: A brief review. Chemik 68:620-628.

67. Cudmore J; Seftel M; Sisler J; Zarychanski R (2014) Methotrexate and trimethoprim-sulfamethoxazole: Toxicity from this combination continues to occur. Can Fam Physician 60:53-56.

68. Höltge S; Kreuzig R (2007) Laboratory testing of sulfamethoxazole and its metabolite acetyl-sulfamethoxazole in soil. Clean - Soil, Air, Water 35:104-110.
69. Radke M; Lauwigi C; Heinkele G; Múrdter TE; Letzel M (2009) Fate of the antibiotic sulfamethoxazole and its two major human metabolites in a water sediment test. Environ Sci Technol 43:3135-3141.

70. Wu Y; Williams M; Smith L; Chen D; Kookana R (2012) Dissipation of sulfamethoxazole and trimethoprim antibiotics from manure-amended soils. J Environ Sci Heal 47:240249.

71. Srinivasan P; Sarmah AK (2014) Dissipation of sulfamethoxazole in pasture soils as affected by soil and environmental factors. Sci Total Environ 479-480:284291.

72. Wu X; Ernst F; Conkle JL; Gan J (2013) Comparative uptake and translocation of pharmaceutical and personal care products (PPCPs) by common vegetables. Environ Int 60:15-22.

73. Pan M; Wong CKC; Chu LM (2014) Distribution of antibiotics in wastewater-irrigated soils and their accumulation in vegetable crops in the Pearl River Delta, Southern China. J Agric Food Chem 62:11062-11069.

74. Fischer M; Thöny B; Leimkühler S (2010) The biosynthesis of folate and pterins and their enzymology. In Comprehensive Natural Products II: Chemistry and Biology; Elsevier Ltd 7:599-648.

75. Perreten V; Boerlin P (2003) A New Sulfonamide Resistance Gene (sul3)in Escherichia coli Is Widespread in the pig population of Switzerland. Antimicrob Agents Chemother 47:1169-1172.

76. Pham TDM; Ziora ZM; Blaskovich MAT (2019) Quinolone antibiotics. Medchemcomm 10:1719-1739.

77. Emmerson AM (2003) The quinolones: decades of development and use. J Antimicrob Chemother 51:13-20.

78. Fàbrega A; Madurga S; Giralt E; Vila J (2009) Mechanism of action of and resistance to quinolones. 2:40-61.

79. Stein GE (1988) The 4-Quinolone Antibiotics: Past, Present, and Future. Pharmacother J Hum Pharmacol Drug Ther 8:301-314.

80. Sharma PC; Jain A; Jain S; Pahwa R; Yar MS (2010) Ciprofloxacin: Review on developments in synthetic, analytical, and medicinal aspects. J Enzyme Inhib Med Chem 25:577-589.

81. Updated surface water Watch List adopted by the Commission | EU Science Hub (accessed on Jul 22, 2020).

82. Trouchon T; Lefebvre S (2016) A Review of Enrofloxacin for Veterinary Use. Open J Vet Med 6:40-58.

83. Ingram PR; Rogers BA; Sidjabat HE; Gibson JS; Inglis TJJ (2013) Co-selection may explain high rates of ciprofloxacin non-susceptible Escherichia coli from retail poultry reared without prior fluoroquinolone exposure. J Med Microbiol 62:1743-1746.

84. Logan BE; Oh SE; Kim IS; Van Ginkel S (2002) Biological hydrogen production measured in batch anaerobic respirometers. Environ Sci Technol 36:2530-2535.

85. Leal RMP; Figueira RF; Tornisielo VL; Regitano JB (2012) Occurrence and sorption of fluoroquinolones in poultry litters and soils from São Paulo State, Brazil. Sci Total Environ 432:344-349. 


\section{Environmental Fate of Antibiotics and Resistance Genes in Livestock Waste}

and Digestate from Biogas Plants

86. Drillia P; Stamatelatou K; Lyberatos G (2005) Fate and mobility of pharmaceuticals in solid matrices. Chemosphere 60:1034-1044.

87. Boxall ABA; Johnson P; Smith EJ; Sinclair CJ; Stutt E et al. (2006) Uptake of veterinary medicines from soils into plants. J Agric Food Chem 54:2288-2297.

88. Picó Y; Andreu V (2007) Fluoroquinolones in soil-risks and challenges. Anal Bioanal Chem 387:1287-1299.

89. Al-marzooq F; Yasim M; Yusof M; Tay ST (2014) Molecular Analysis of Ciprofloxacin Resistance Mechanisms in Malaysian ESBL-Producing Klebsiella pneumoniae Isolates and Development of Mismatch Amplification Mutation Assays ( MAMA ) for Rapid Detection of gyrA and parC Mutations.

90. Robicsek A; Strahilevitz J; Jacoby GA; Macielag M; Abbanat D (2006) Fluoroquinolone-modifying enzyme: A new adaptation of a common aminoglycoside acetyltransferase. Nat Med 12:83-88.

Citation: Barra Caracciolo A; Visca A; Massini G; Patrolecco L; Mazzurco Miritana V at el. (2020) Environmental Fate of Antibiotics and Resistance Genes in Livestock Waste and Digestate from Biogas Plants. Enviro Sci Pollu Res Mang: ESPRM-102. 